\title{
Schwannoma Tongue
}

Seema Monga, Junaid Nasim Malik, Arun Parkash Sharma From the Department of ENT \& HNS, HIMSR \& HAHC Hospital, Jamia Hamdard, Delhi-1 10062 , India.

\section{Abstract:}

Schwannoma of the tongue is a relatively rare tumor of the head and neck. We report a case of schwannoma of tongue in a young male who presented with a slowly progressive painless mass over the left anterolateral border of tongue without any impairment of tongue movement. Fine needle aspiration cytology of this lesion was suggestive of a benign nerve sheath tumor. Complete excision of the mass through an intraoral approach with primary closure was done. Definitive histopathological examination confirmed the diagnosis of schwannoma.

Key words: Nerve Sheath Neoplasms, Neurilemmoma, Fine Needle Biopsy, Head, Neck.

\section{Introduction}

Schwannomas (Neurilemmomas or neurinomas) are benign encapsulated nerve sheath neoplasms composed of Schwann cells first described by Verocay in 1908 [1]. It usually presents as a solitary and encapsulated tumor and can virtually affect any peripheral autonomic or cranial nerve (except olfactory and optic) [2]. 25-40 percent of all schwannomas are considered to affect the head and neck region with the parapharyngeal space being the most common location. Only one percent cases are intraoral. The intraoral lesions show a predilection for the tongue, followed by the palate, buccal mucosa, lip and gingiva. Schwannomasof the tongue typically present in the third decade of life and display no gender predilection. The treatment of choice is surgical excision of the tumor most commonly by transoral approach [3]. Schwannomas generally do not recur if completely excised.
We report a case of schwannoma of the tongue in a young male presenting as a slowly enlarging mass. It was managed by complete surgical excision via intraoral approach. The patient has been under our follow up for past 6 months and shows no evidence of recurrence.

\section{Case Report}

A 20 year old male presented with otherwise asymptomatic slow growing swelling on left border of tongue of six months duration. It was a painless swelling and didn't interfere with normal functioning of the tongue. Physical examination revealed a $2 \times 1 \mathrm{~cm}$ normal mucosa covered globular, smooth, firm, non-tender swelling on left anterolateral aspect $1 \mathrm{~cm}$ behind the tip of tongue [Fig.1]. There was no associated lymphadenopathy. Haematological

\section{Corresponding Author: Dr. Seema Monga}

Email: dr.seema.monga@gmail.com

Received: June 5,2013 | Accepted: June 11,2013 | Published Online: July 15, 2013

This is an Open Access article distributed under the terms of the Creative Commons Attribution License (creativecommons.org/licenses/by/3.0)

Conflict of interest: None declared | Source of funding: Nil | DOl: http://dx.doi.org/10.17659/01.2013.0052 
and biochemical investigation were within normal limits. Fine needle aspiration cytology suggested the swelling as a benign spindle cell lesion, possibly neurogenic in origin, suggestive of schwannoma. The lesion was surgically excised under general anaesthesia via transoral approach. Grossly the mass was well encapsulated, and had firm gray white cut surface with cystic areas. Microscopically the tumour was composed of spindle shaped cells displaying elongated nuclei with mild pleomorphism. Areas of pallisading arrrangement of nuclei suggestive of Verocay bodies were noted. Histological examination confirmed the diagnosis of schwannoma tongue. In view of histopathological diagnosis, a thorough physical examination was made to rule out multiple tumors of neural origin and it came out to be negative. Healing was uneventful without any loss of function.

\section{Discussion}

Peripheral nerve sheath tumors can be benign or malignant. Benign peripheral nerve sheath tumors include schwannoma and neurofibroma, latter usually found in individuals with neurfibromatosis type 1. Schwannomas are usually solitary but multifocal lesions may occur in association with von Recklinghausen disease and schwannomatosis, a non-hereditary disease characterized by multiple subcutaneous or intradermal schwannomas along with tumors of internal organs [4].

Within the tongue, schwannomas may arise from the hypoglossal nerve, glossopharyngeal nerve or the lingual nerve. Identification of the originating nerve may be difficult [5]. Schwannomas are usually slow growing, smooth surfaced, solitary and asymptomatic lesions of variable size. They usually presents as a painless mass, although pain and paresthesias may occur. Other symptoms like disturbance in mastication, phonation and dysphagia might be present depending upon location and size of the tumour. Large size schwannomas and those

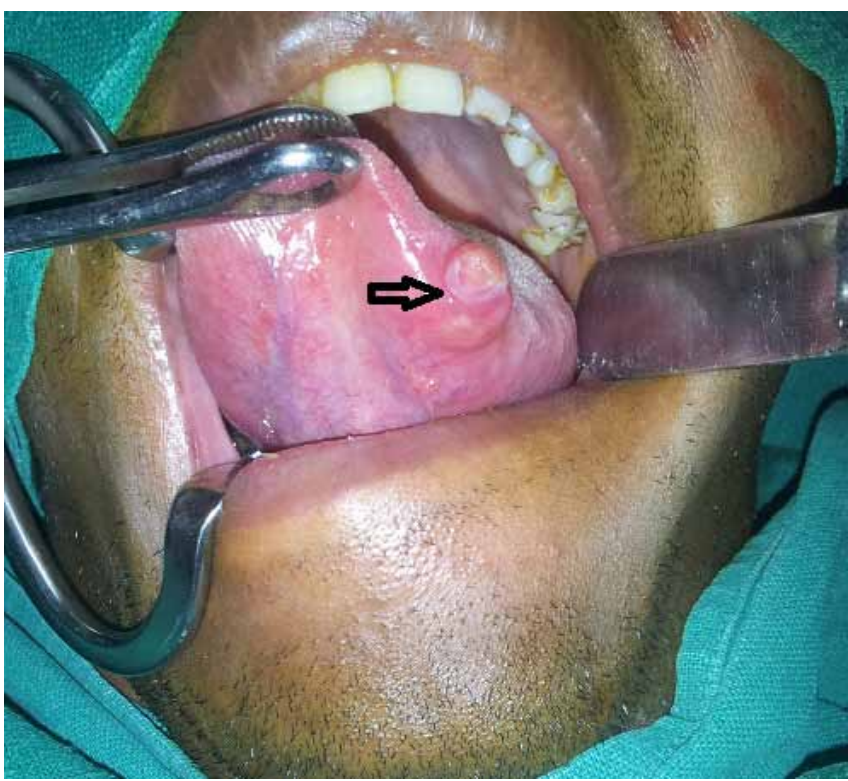

Fig.1: Per-operative photograph showing schwannoma on left anterolateral border tongue.

present in the posterior two thirds of tongue are more likely to produce debilitating symptoms [6]. In our patient, since the size of the lesion was small and it was located in the anterolateral border of tongue it did not cause many symptoms.

Differential diagnosis are other benign, slow growing, macroscopically well circumscribed lesions of the tongue including neurofibroma, traumatic neuroma, fibroma, lipoma, leiomyoma etc. [7]. In some cases, squamous cell carcinoma, sarcomas and glandular malignant processes may present with similar clinical features. Diagnostic investigations include MRI or CT scan and fine needle aspiration cytology. The definitive diagnosis is based on histopathological findings. Schwannomas have a distinctive pattern of compact cellularity arranged with palisading nuclei (Antoni A pattern) alternating with a more loosely arranged hypocellular pattern (Antoni B pattern) [8]. The absence of large multipolar fibroblasts, reticulin and a mucous matrix distinguishes schwannoma from other similar histological entities like meningioma, leiomyoma, 
palisaded myofibroblastoma and pleomorphic hyalinising angiectatic tumour of soft tissue [5]. In our patient, fine needle aspiration cytology of the mass revealed findings of a benign neurogenic tumor suggestive of a schwannoma. MRI could not be done due to financial constraints of the patient.

Treatment is always surgical and requires an excision or enucleation of the tumor. Although several approaches like transhyoid, suprahyoid, or submandibular approaches have been used, transoral approach remains the standard approach for excision except in some cases of base of tongue schwannomas [9-11]. Our case was similarly managed by complete excision of the tumor via transoral approach. It has a good prognosis as the tumor is benign and recurrence is rare unless the resection of the tumor is incomplete. Few cases of malignant transformation of head and neck schwannomas have been reported, including one in the tongue [12]. Das Gupta and Brasfield found an incidence of $8 \%$ of malignant schwannomas and Ghosh et al reported an incidence of $13.9 \%[13,14]$.

\section{Conclusion}

Schwannomas although rare should be included in the differential diagnosis of well circumscribed tongue masses. The definitive diagnosis requires a histopathological evaluation. Treatment is complete surgical excision of the lesion which does not result in any recurrence.

\section{Consent}

The authors have taken the patient's informed consent for the case report to be published.

\section{References}

1. Enzinger FM, Weiss SW. Benign tumours of peripheral nerves. In: Enzinger FM, Weiss SW (ed). Soft tissue tumours. 4th ed. Mosby: St. Louis; 1995.p.821-888.

2. Zachariades N. Schwannoma of the oral cavity: review of the literature and report of a case. $J$ Oral Med. 1984;39:41-43.

3. Cohen $M$, Wang MB. Schwannoma of the tongue: two case reports and review of literature. Eur Arch Otorhinolarngol. 2009;266:1823-1829.

4. Robert OG. The oral cavity. In: Steven GS (ed). Principle and practice of surgical pathology and cytology, vol.2. New York: Churchill Livingstone;1997.p.1399-1460.

5. Bansal R, Trivedi P, Patel S. Schwannoma of the tongue. Oral Oncol Extra. 2005;41:15-17.

6. Nisa L, Buren TV, Tiab A, Giger R. Giant Plexiform Schwannoma of the tongue. Case Reports in Otolaryngology. $2011 ; 2011$ :762524.

7. Nelson W, Chuprevich T, Galbraith DA. Enlarging tongue mass. J Oral Maxillofac Surg. 1998;56:224-227.

8. Cherrick HM, Eversole LR. Benign neural sheath neoplasm of the oral cavity. Oral Surg Oral Med Oral Pathol. 1971;32:900-909.

9. deBree R, Westerveld GJ, Smeele LE. Submandibular approach for excision of a large Schwannoma in a base of tongue. Europe Arch Otorhinolaryngol. 2000;257:283-286.

10. Ying Y-LM, Zimmer LA, Myers EN. Base of tongue Schwannoma:a case report. Laryngoscope. 2006;1 16:1 284-1287.

11. Hsu YC, Hwang CF, Hsu RF, Kuo FY, Chen CY. Schwannoma (Neurilemmoma) of the tongue base. Acta Otolaryngol. 2006; 126:861-865.

12. Piatelli A, Angelone A, Pizzicannella G, Piatelli M. Malignant Schwannoma of the tongue: report of a case and review of literature. Acta Stomatol Belg. 1984;81:213-225.

13. Das Gupta TK, Brasfield RD. Solitary Schwannoma. Ann Surg. 1976;171:419.

14. Ghosh BC, Ghosh L, HuvosAG, Fornet JA. Malignant Schwannoma: A clinicopathologic study. Cancer. 1973;31:184. 